\title{
EFFECT OF ANTITUMOR DRUGS IN LOW CONCENTRATIONS ON THE BIOLOGICAL, IMMUNOPHENOTYPIC AND CYTOGENETIC CHARACTERISTICS OF HUMAN COLON CANCER CELLS IN VITRO
}

\author{
N. Bezdieniezhnykh ${ }^{1, *}$, O. Kovalova ${ }^{1}$, O. Lykhova ${ }^{1}$, R. Kocherga ${ }^{1}$, A. Vorontsova ${ }^{1}$, V. Zhylchuk ${ }^{2}$, \\ G. Maksimyak', Yu. Kudryavets ${ }^{1}$ \\ ${ }^{1}$ R.E. Kavetsky Institute of Experimental Pathology, Oncology and Radiobiology, NAS of Ukraine, Kyiv 03022, Ukraine \\ ${ }^{2}$ Rivne Regional Oncology Center, Rivne 33003, Ukraine
}

\begin{abstract}
Objective: To estimate the impact of the low-dose anticancer drugs (ACD) with the different mechanisms of action and human interferon (IFN) alpha $2 \mathrm{~b}$ on the biological properties, immunophenotypic and cytogenetic characteristics of colon cancer cells in vitro. Materials and Methods: The study was performed on human colon cancer cell lines COLO 205, HT-29 and 3C-P treated with ACD and IFN in subtoxic concentrations. Expression of CD44, N-cadherin, vimentin, $\beta$-catenin, ERCC1 and Slug was assessed by immunocytochemical method. Using cytogenetic analysis, the numbers of mitoses, cells with micronuclei, apoptotic cells and cells with nuclear protrusions were studied. Results: The prolonged exposure (up to 30 days) of colon cancer cells to low-dose ACD (0.2-0.5 $\mu \mathrm{g} / \mathrm{ml} \mathrm{cisplatin} \mathrm{and}$ $0.1-0.2 \mu \mathrm{g} / \mathrm{ml}$ irinotecan) in combination with IFN (500-1000 IU/ml) led to 37-fold decreased colony-forming activity of these cell and 10-fold reduction of the number of cells expressing mesenchymal protein markers (N-cadherin, vimentin). Also, in COLO 205 cells treated with ACD and IFN the number of SLUG- and CD44-positive cells decreased by 92 and by 85\%, respectively. Long-term cultivation of HT-29 cells in the presence of cisplatin and IFN resulted in 5-fold suppression of ERCC1 expression. The cytogenetic analysis has shown that the ACD, IFN and their combinations in subtoxic concentrations caused significant genotoxic effect, suppression of cell proliferation and accumulation of cells with micronuclei. The sensitivity of colon cancer cells to ACD in standard cytotoxic concentrations did not change after prolonged low-dose exposure. Conclusion: The data showed that the prolonged action of the low doses of ACD on human colon cancer cells resulted in the suppression of cell proliferation, colony-forming activity in soft agar, expression of epithelialmesenchymal transition-associated markers and significant cytogenetic changes.
\end{abstract}

Key Words: colon cancer, tumor cells, epithelial-mesenchymal transition, malignant phenotype, anticancer drugs, ERCC1, micronuclei.

In clinical practice the standard chemotherapy of cancer patients is limited by its high toxicity and the development of anticancer drug (ACD) resistance. Therefore, it is considered important to implement metronomic chemotherapy regimen, in which the ACD are administered in low doses at short intervals [1-4]. The ACD doses vary in rather wide range and depend on the ACD, tumor type and stage etc., but such doses are always much lower (5-20 times) than the doses used in standard chemotherapy. Metronomic chemotherapy regimen allows reducing the level of the overall toxicity of chemotherapy and side effects. It is known that low doses of ACD had no cytostatic effect toward tumor cells, but retain high activity as inhibitors of neoangiogenesis [5]. It is believed that metronomic lowdose regimen (MLDR) is targeted not against tumor cells, which are genetically unstable and form resistant to chemotherapy phenotypic variants, but against genetically stable and highly sensitive to chemotherapy normal endothelial cells required for tumor growth $[6,7]$. The authors consider following mechanisms of MLDR action: its antiproliferative effect against endothelial cells, blockage of VEGF, inhibiting of matrix metalloproteinases and tissue plasminogen activator, and increased endogenous thrombospondin 1 result-

Submitted: February 18, 2017.

*Correspondence: E-mail: beznalia@mail.ru

Abbreviations used: ACD - anticancer drugs; CFA - colony-forming activity; $\mathrm{CP}$ - cisplatin; EMT - epithelial-mesenchymal transition; IFN - interferon; IT - irinotecan; FBS - fetal bovine serum; MLDR - metronomic low-dose regimen; $\mathrm{MN}$ - micronuclei. ing in apoptosis of CD36-positive endothelial cells [8]. By our opinion, this list of MLDR mechanisms could be continued, because even in the absence of direct cytotoxic effect of ACD one could not exclude its effect on tumor cells by modifying their biological characteristics. It is logical to assume that the ACD as a biologically active substance will affect not only tumor cells through induction of cell death, but also through modification of their characteristics, including the reversal of their malignancy. In particular, our previous studies have shown that type I interferon (IFN) at the doses that do not affect the growth activity, proliferative potential and viability of cells in general, exerts long-term effects on tumor cells caused by suppression of their malignant potential through inhibition of proteins and transcription factors associated with epithelial-mesenchymal transition (EMT) [9, 10]. Biological characteristics and immunophenotype of tumor cells to a large extent determine the rate of tumor growth, its drug sensitivity, and intensity of metastasis. In turn, the EMT plays a key role in tumorigenicity, metastatic cascade and drug resistance of tumors. Accordingly, the assessment of MLDR impact into biological characteristics of tumor cells and the expression of proteins involved in EMT regulation is an actual problem. In our previous study [3], a positive result of MLDR in the treatment of patients with metastatic colorectal cancer associated with its antiangiogenic therapeutic effect was demonstrated. It was shown that the mostly effective MLDR schemes were based on the use of platinum drugs and camptothecin deriva- 
tives in combination with IFN, and resulted in disease stabilization, a significant increase in survival period of patients with metastatic colorectal cancer and provided a relatively high quality of their life.

These important clinical results of MLDR use and new data about activity of IFN as an inhibitor of EMT in tumor cells were the prerequisite for the in vitro study of influence of IFN and ACD with different mechanisms of action, including derivatives of camptothecin and platinum drugs, on the biological characteristics and immunophenotypic profile of colon cancer cells. In this case, special attention was focused on the influence of ACD at the doses that corresponded to these in the blood of patients treated with MLDR - much lower than the IC50, on EMT-associated proteins, and consequently, on the biological and cytogenetic characteristics of tumor cells.

\section{MATERIALS AND METHODS}

Cell lines. Cells of human colon cancer (COLO 205, HT-29 cell lines) and new stable cell line from primary culture of ascitic fluid of the patient with colorectal adenocarcinoma generated by 20 passages in vitro (3C-P cell line) were obtained from the Bank of Cell Lines of Human and Animal Tissues, R.E. Kavetsky Institute of Experimental Pathology, Oncology and Radiobiology, NAS of Ukraine (Kyiv, Ukraine). COLO 205 cells were maintained in RPMI-1640 medium (Sigma, USA) supplemented with $10 \%$ fetal bovine serum (FBS) (PAA, Austria) and $40 \mu \mathrm{g} / \mathrm{ml}$ gentamicin (Sigma, USA). HT-29 and $3 \mathrm{C}-\mathrm{P}$ cell lines were maintained in plastic flasks (TPP, Italy) in DMEM with $4 \mathrm{mmol} / \mathrm{l}$ L-glutamine (PAA, Austria) and $10 \%$ of FBS (PAA, Austria) and $40 \mu \mathrm{g} / \mathrm{ml}$ gentamicin (Sigma, USA). The cells were incubated at $37^{\circ} \mathrm{C}$ in a humidified atmosphere with $5 \%$ $\mathrm{CO}_{2}$. Cells were detached with EDTA solution (Sigma, USA) and cultured by the standard method [11].

Modified cell sublines were obtained in our laboratory by treatment of COLO 205, HT-29 and 3C-P cells with subtoxic doses (10-20 times lower than IC50 established for each culture) of cisplatin (CP), irinotecan (IT) and human recombinant IFN- $\alpha 2 b$ for 30 days. The final concentration of drugs were as following: platinum drugs (cisplatin) $-0.2-0.5 \mu \mathrm{g} / \mathrm{ml}($ IC50 $-8 \mu \mathrm{g} / \mathrm{ml}$ ), camptothecin derivative (irinotecan) $-0.1-0.2 \mu \mathrm{g} / \mathrm{ml}$ (IC50 - $2.5 \mu \mathrm{g} / \mathrm{ml})$, and IFN (laferobion) - 500$1000 \mathrm{IU} / \mathrm{ml}$ (IC50 - 10,000 IU/ml).

Analysis of growth kinetic of tumor cells. Studied cells $\left(1 \cdot 10^{4}\right.$ cells $\left./ \mathrm{ml}\right)$ were seeded in 24-wells plates (TPP, Italy) in $1.5 \mathrm{ml}$ of complete DMEM or RPMI- 1640 and incubated for 8 days. Every $24 \mathrm{~h}$ the cells were detached with EDTA solution (BioTestMed, Ukraine) from three wells at each time point, stained with trypan blue solution (HyClone, USA) and counted in hemocytometer.

Semisolid agar colony assay. The assay was conducted in parallel wells of 6 -well plates. Base layers of $4 \mathrm{ml}$ of $0.5 \%$ agar (Difco, USA) were prepared on RPMI- 1640 medium with $10 \%$ FBS. A 2 ml overlayer of $0.33 \%$ agar containing studied cells $\left(2 \cdot 10^{3}\right)$ in DMEM medium with $10 \%$ FBS and $40 \mu \mathrm{g} / \mathrm{ml}$ gentamicin was then applied and the plates were incubated at $37^{\circ} \mathrm{C}$ in a humidified atmosphere containing $5 \% \mathrm{CO}_{2}$. After 14 days of the incubation, the plating colonies were stained with $0.2 \%$ methylthiasoliletetrazolium solution (Sigma, USA) at $37^{\circ} \mathrm{C}$ for $2 \mathrm{~h}$. After that, the number of colonies was counted in each well using binocular magnifiers BM-51-2 (LOMO, Russia). Colonyforming activity (CFA) of studied cells was determined by the formula:

$$
C F A=(A / B) \cdot 100 \% \text {, }
$$

wherein $A$ - the number of colonies per well; $B$ the number of cells planted in semisolid agar per well.

Immunocytochemical assay. Phenotypic changes of the studied cells after their prolonged treatment with ACD and IFN were determined by counting the cells expressing CD44, $\mathrm{N}$-cadherin, vimentin, $\beta$-catenin, ERCC 1 and Slug. Control and modified cells were placed on the glass slides (cytospin samples) and the analysis was made by the standard method with the use of monoclonal antibodies against CD44 (Diagnostic BioSystems, USA), $N$-cadherin, vimentin, $\beta$-catenin (ThermoScientific, USA), ERCC1 (Abcam, USA), Slug (GenTex, USA). Ultra Vision LPValue Detection system (Thermo Scientific, USA) was used to visualize the reaction of antigen/antibody. DAB Quanto (3,3-diaminobenzydyn) (Thermo Scientific, USA) was used as a chromogen. Stained preparations were analyzed using binocular Axiostar Plus microscope and immersion oil at the magnification $\times 100$ and photographed using camera Canon PowerShot G5. Expression of mentioned proteins was evaluated semiquantitavely using $\mathrm{H}$-score system accounting the number and intensity of the stained cells. The percentage of the stained cells was multiplied by score number corresponding to the staining intensity $(0=$ none, $1=$ weak, $2=$ moderate, $3=$ strong). The resulting score ranged from 0 (no stained cells) to 300 (diffuse intense staining of cells), and $\mathrm{H}$-score was calculated as (percentage of cells stained at intensity $1 \times 1)+($ percentage of cells stained at intensity $2 \times 2)+($ percentage of cells stained at intensity $3 \times 3$ ) [12].

Cytogenetic analysis. Studied cells were detached with EDTA solution and incubated for 40 min in hypotonic solution of $\mathrm{KCl}(0.54 \%)$ (Reahim, Ukraine) at $37^{\circ} \mathrm{C}$. After that the cells were fixed with methanol (Reahim, Ukraine) and acetic acid (Chemlaborreactiv, Ukraine) at a ratio of $3: 1$. The procedure of fixing was performed in triplicate. Cell suspension in the fixing solution was dripped on the cold wet glass slides and dried. Samples were stained with Giemsa stain (Merck, Germany). The cytogenetic preparations were analyzed using binocular Axiostar Plus microscope (Carl Zeiss, Germany) at the magnification $\times 100$ and photographed using camera Canon PowerShot G5 (UK). The following characteristics were studied: number of mitoses, cells with micronuclei (MN), apoptotic cells and cells with nuclear protrusions. These indicators were counted per 1000 cells, and the results are expressed in per mille (\%o) [13]. 
Statistical analysis. Statistical analysis of the data was performed by the Student $t$-test using Statistica 6.0 program. The data are presented as $\mathrm{M} \pm$ SD. Statistical significance was set at $p \leqslant 0.05$.

\section{RESULTS AND DISCUSSION}

To investigate the impact of subtoxic doses of cytostatics on colorectal cancer cells, as potential modifiers of their malignant phenotype, we have used the ACD usually applied in the clinic for the treatment of patients with colorectal cancer - camptothecin derivative and a platinum drug. These drugs were used in mono- or combined regimes because they have different mechanisms of action and could exert a synergistic effect [14, 15].

For example, CP is a DNA crosslinker that changes the DNA structure and functions, inhibits its synthesis, thereby leading to cell death. IT is a semi-synthetic derivative of camptothecin that is a specific inhibitor of topoisomerase-1, and causes damage to the singlestranded DNA and blocks its replication. Also, we have investigated the impact of the low doses of IFN on colon cancer cells. IFN - multifunctional cytokine, which exerts antiproliferative and antiangiogenic effects and is capable to modify the phenotype of tumor cells, reduce their tumorigenicity [9] and increase their sensitivity to ACD.

Firstly, we have studied the morphology, growth and immunophenotypic patterns of COLO 205 cells after their exposure to the abovementioned agents. This model was selected because of its initial biological characteristics, such as the dominance of mesenchymal features. Our observations showed that after addition of the investigated drugs or their combinations, the number of COLO 205 living cells did not change statistically significant compared to control cells within the first 10 days of cultivation, but after 15 days of cultivation, the rate of cell growth started to decline. It should be mentioned that the most significant antiproliferative effect was observed in the cells exposed to low-dose IT (Fig. 1).

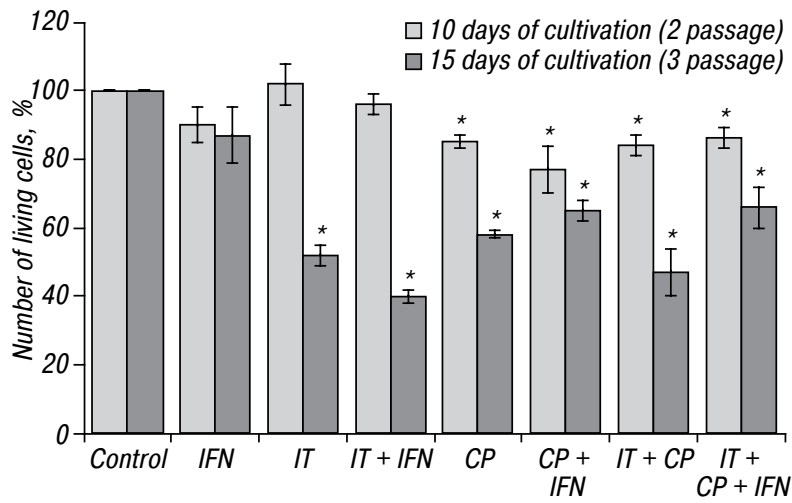

Fig. 1. Percentage of COLO 205 living cells after their cultivation with subtoxic doses of ACD compared to control. ${ }^{*} p<0.05 \mathrm{com}$ pared with control cells

Significant changes in the morphology of these cells and their adhesion to the substrate was observed only after 2 weeks of COLO 205 cultivation in the presence of CP, IT, and IFN. The most significant impact on the morphology of COLO 205 cells was observed in the case of treatment with IFN and CP (Fig. 2).
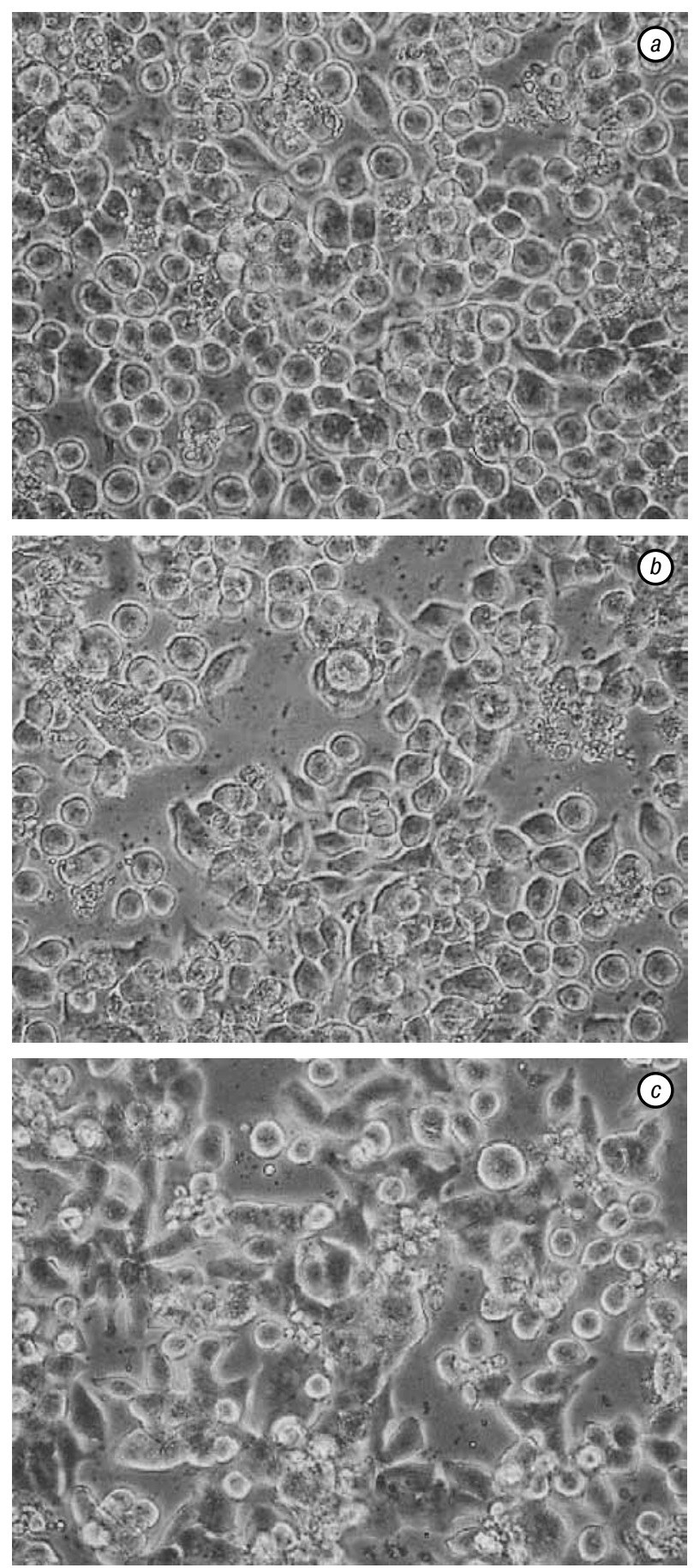

Fig. 2. Morphology of live COLO 205 cells: control cells (a), cells treated with IFN $(b)$ or $\mathrm{CP}(c)$ within 14 days, $\times 320$

The malignancy of these cells was studied in vitro by semisolid agar colony assay. Our investigation has shown that treatment of COLO 205 cells with MLDR and IFN has resulted in a significant inhibition of their ability to form colonies in semisolid agar (Table 1). In this case, the most significant effect was caused by IT and complex action of these ACD and cytokine.

Thereby, the results of semisolid agar colony assay in vitro showed the suppression of the features of tumor cell malignancy upon their exposition to subtoxic doses of ACD and IFN. Also, we have studied immunophenotypic features of the cells, including adhesion and cytoskeleton proteins associated with EMT such as $\mathrm{E}$ - and $\mathrm{N}$-cadherins, $\mathrm{CD} 44, \beta$-catenin, transcription 
factor Slug, which is directly related to the regulation of cell adhesion, invasion and migration, and protein that is responsible for drug resistance of tumor cells to some ACD - ERCC1 (DNA excision repair protein) (Table 2, Fig. 3, 4).

Table 1. CFA of COLO 205 cells after their prolonged exposure to low doses of ACD and IFN

\begin{tabular}{lc}
\hline & Treatment \\
\hline Control & CFA, \% \\
IFN & $9.25 \pm 0.62$ \\
IT & $7.25 \pm 0.48$ \\
CP & $1.66 \pm 0.33^{\star \star}$ \\
IT + CP & $3.25 \pm 0.25^{\star}$ \\
IT + IFN & $1.25 \pm 0.25^{\star \star}$ \\
CP + IFN & $1.00 \pm 0^{\star \star \star}$ \\
IT + CP + IFN & $2.50 \pm 0.29^{\star}$ \\
\hline
\end{tabular}

Note: The difference is statistically significant compared with control COLO 205 cells; ${ }^{\star} p<0.005 ;{ }^{* \star} p<0.002 ;{ }^{* \star *} p<0.001$.

Table 2. Immunophenotypic profile of COLO 205 cells after prolonged exposure to the subtoxic doses of ACD and IFN

\begin{tabular}{|c|c|c|c|c|c|c|c|c|}
\hline \multirow{3}{*}{ Antigen } & \multicolumn{8}{|c|}{ Drugs } \\
\hline & 을 & IFN & IT & $\mathrm{CP}$ & $\begin{array}{c}\mathrm{IT}+ \\
\mathrm{CP}\end{array}$ & $\begin{array}{l}\text { IT + } \\
\text { IFN }\end{array}$ & $\begin{array}{c}\mathrm{CP}+ \\
\mathrm{IFN}\end{array}$ & $\begin{array}{c}\mathrm{IT}+ \\
\mathrm{CP}+ \\
\mathrm{IFN}\end{array}$ \\
\hline & \multicolumn{8}{|c|}{ Points (H-Score) } \\
\hline$\overline{\mathrm{N} \text {-cadherin }}$ & $\begin{array}{c}108 \pm \\
22\end{array}$ & $<10$ & $<10$ & $\begin{array}{c}32 \pm \\
6^{\star}\end{array}$ & $<10$ & $<10$ & $54 \pm 9$ & $<10$ \\
\hline CD44 & $\begin{array}{c}118.6 \pm \\
3.6\end{array}$ & $\begin{array}{c}8.8 \pm \\
2.2^{\star \star \star}\end{array}$ & $\begin{array}{c}105.4 \pm \\
4.8\end{array}$ & $\begin{array}{c}25 \pm \\
1.7^{\star \star \star}\end{array}$ & $\begin{array}{l}72.2 \pm \\
2.3^{\star *}\end{array}$ & $\begin{array}{c}5.3 \pm \\
2.3^{\star \star \star}\end{array}$ & $\begin{array}{l}12.3 \pm \\
2.2^{\star \star \star}\end{array}$ & $\begin{array}{l}14.6 \pm \\
1.7^{\star \star \star}\end{array}$ \\
\hline Slug & 300 & $<10$ & $<10$ & $\begin{array}{c}194 \pm \\
3.2^{\star \star \star}\end{array}$ & $<10$ & $<10$ & $<10$ & $<10$ \\
\hline
\end{tabular}

Note: The difference is statistically significant compared with control COLO 205 cells; ${ }^{\star} p<0.05 ;{ }^{* *} p<0.002,{ }^{\star \star *} p<0.001$.

As it was recently accepted, these proteins determine the EMT status of cells and participate in the formation of their invasive-metastatic phenotype. For example, $\mathrm{N}$-cadherin is a $\mathrm{Ca}$-dependent transmembrane protein of classical cadherin family, regulating cell adhesion, but in contrast to E-cadherin, it promotes the separation of cells from the original tumor mass, their migration, and initiates the metastatic cascade. The other adhesion molecules, CD44 antigen also has direct relevance to the invasive and migratory activity of tumor cells and is used as a marker of progression and metastasis in many cancer types, including breast cancer cells with the phenotype of CD44 ${ }^{+} \mathrm{CD} 24^{-}$ considered as "cancer stem cells" [16]. A potential regulator of cell adhesion and migration, transcription factor Slug plays an important role in the physiological (embryogenesis) and pathological (malignancy) EMT of cells and is a suppressor of E-cadherin promoter through its inhibition [17]. It is known that an increased expression of Slug provides tumor cells with the mesenchymal phenotype and high metastatic potential [18]. To study the effects of subtoxic doses of ACD on tumor cell phenotype, expression of abovementioned proteins was assessed in COLO 205, HT-29, and 3C-P cells.

The results of the study of immunophenotypical characteristics of the cells are presented in Tables 2, 3. As it is shown in Table 2, the prolonged exposure of the COLO 205 cells to IT and IFN in monoregimen or in combinations resulted in significant reduction of the number of $\mathrm{N}$-cadherin-positive cells; the action of $\mathrm{CP}$ also decreased the expression of this antigen but at the lower level. Regarding expression of CD44, stem cell marker, the lowest effect was observed in the case of low-dose IT: the expression of CD44 decreased by $11.1 \%$, while the most significant effect was registered in the case of combined action of IFN and the cytostatics. The most interesting observation was almost complete inhibition the Slug expression in COLO 205 cells under the influence of subtoxic doses of the studied drugs used either in monoregimen or in combination; only the influence of $\mathrm{CP}$ did not reduce significantly number of Slug-positive cells (35.4\%).

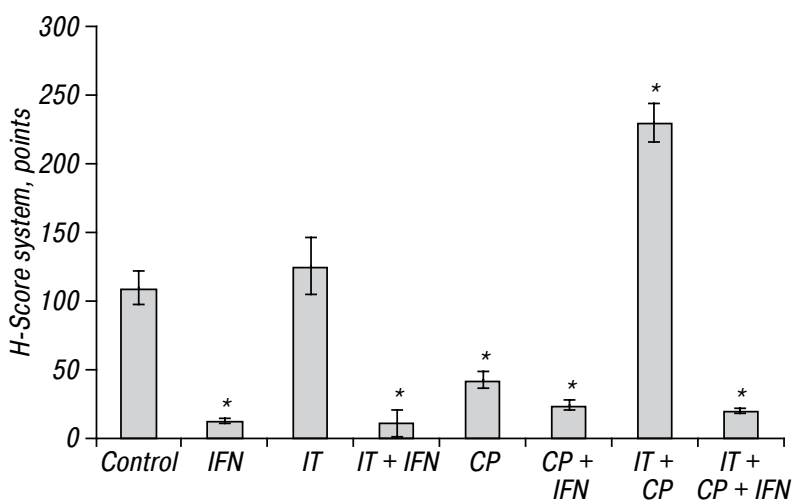

Fig. 3. Immunocytochemical analysis of ERCC1 expression in COLO 205 cells after prolonged (30 days) exposure to the subtoxic doses of ACD. ${ }^{*} p<0.05$ compared with control cells

Another studied antigen was ERCC1, a protein that takes part in DNA repair. According to the literature, an increased expression of this protein in colon cancer cells is associated with their high resistance to platinum-based chemotherapy $[19,20]$ and is the basis for the indication of IT (camptothecin) to such patients. As we have shown (see Fig. 3, 4), the use of IFN and its combination with IT and $\mathrm{CP}$ resulted in the almost complete disappearance of ERCC1-positive cells. The action of $\mathrm{CP}$ and $\mathrm{CP}$ combined with IFN led to significant decrease the number of ERCC1-positive cells, while the prolonged action of IT and $\mathrm{CP}$ combination resulted in an increased number of ERCC1-positive cells.

The changes of immunophenotypic features of HT29 cells with predominantly epithelial characteristics are shown in Table 3. Immunocytochemical analysis of ERCC1 expression in HT-29 cells revealed significantly increased the number of ERCC1-positive cells

Table 3. Immunophenotypic profile of HT-29 cells after prolonged exposure to the subtoxic doses of ACD and IFN

\begin{tabular}{|c|c|c|c|c|c|c|c|}
\hline \multirow{3}{*}{ Antigen } & \multicolumn{7}{|c|}{ Drugs } \\
\hline & Control & IFN & IT & $\mathrm{IT}+\mathrm{CP}$ & IT + IFN & $\mathrm{CP}+\mathrm{IFN}$ & $\mathrm{IT}+\mathrm{CP}+\mathrm{IFN}$ \\
\hline & \multicolumn{7}{|c|}{ Points (H-Score) } \\
\hline$\overline{\mathrm{CD} 44}$ & $120.0 \pm 11.6$ & $110.0 \pm 4.0$ & $255.0 \pm 16.5^{\star \star}$ & $205.0 \pm 9.0^{*} \quad 225.0 \pm 11.0^{* *}$ & $230.0 \pm 17.5^{\star}$ & $210.0 \pm 8.4^{\star \star}$ & $198.0 \pm 2.0^{\star \star}$ \\
\hline $\begin{array}{l}\text { Slug (localization } \\
\text { in cytoplasm) }\end{array}$ & $34.0 \pm 1.6$ & $<10$ & $21.0 \pm 7.0$ & $134.0 \pm 8.6^{* \star *} 174.0 \pm 11.0^{\star * *}$ & $<10$ & $<10$ & $62.0 \pm 4.0^{\star \star}$ \\
\hline
\end{tabular}

Note: The difference is statistically significant compared with control HT-29 cells; ${ }^{\star} p<0.02 ;{ }^{* \star} p<0.01 ;{ }^{* \star \star} p<0.002$. 

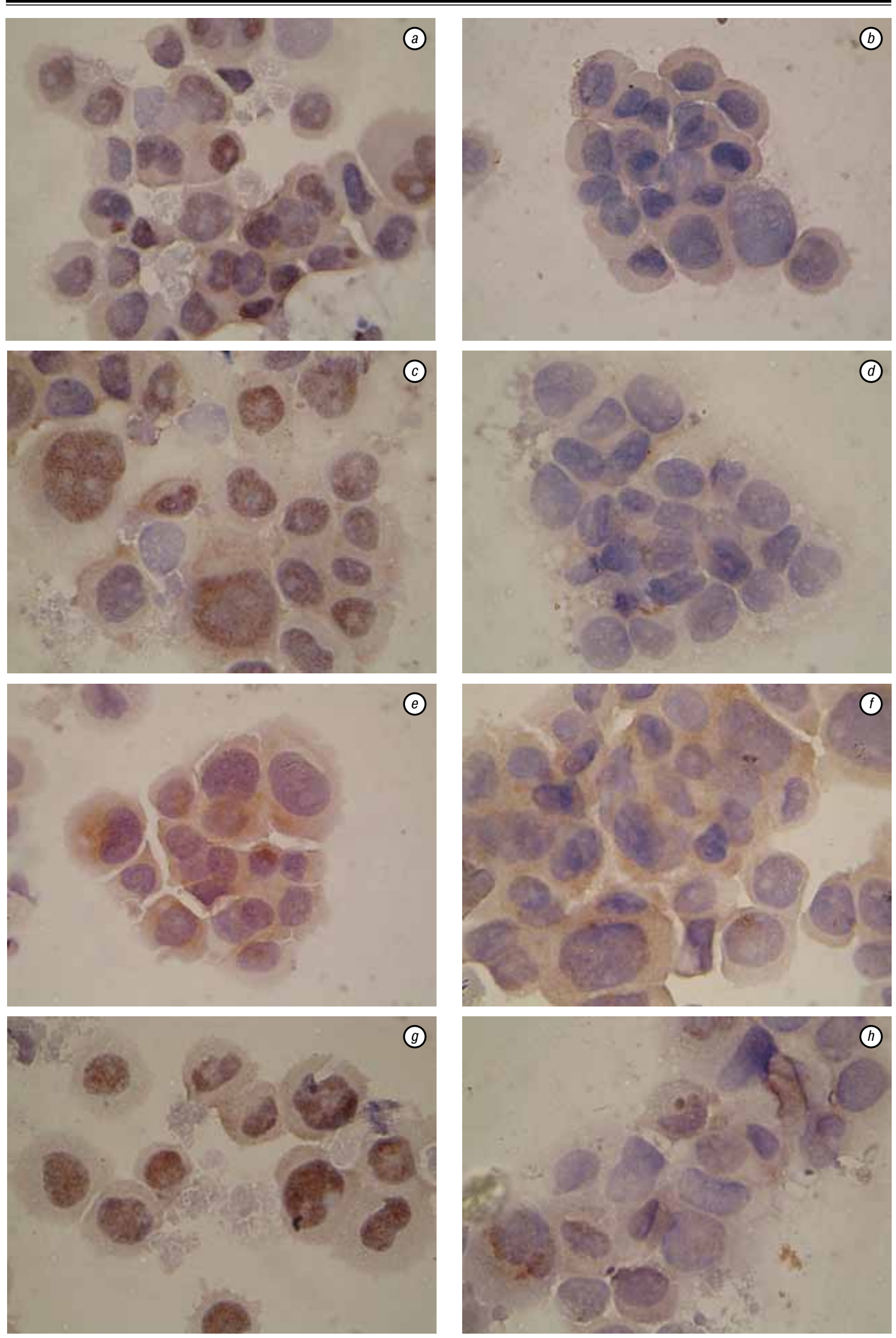

Fig. 4. Immunocytochemical analysis of ERCC 1 expression in COLO 205 cells after prolonged ( 30 days) exposure to the subtoxic doses of ACD. a: control cells; $b$ : + IFN; $c$ : + IT; $d:$ IT + IFN; $e:+$ CP; $f:$ CP + IFN; $g$ : IT + CP; $h$ : IT + CP + IFN (× 1000) 
exposed to IT or IT + CP (Fig. 5). The same trend was observed in COLO 205 cells, although in the case of combined action of IT with IFN a significant reduction in the number of ERCC1-positive cells was noted, whereas in HT-29 cells such effect wasn't observed. A significant decrease of ERCC1-positive cells was observed only if IFN was used in monoregimen or in combination with CP. Expression of E-cadherin did not differ significantly between the control cells and cells treated with ACD (approximately 180-220 points by the H-Score system). We suppose that this fact evidences on a higher stability of cells with the dominance of epithelial characteristics $v s$ these with mesenchymal characteristics.

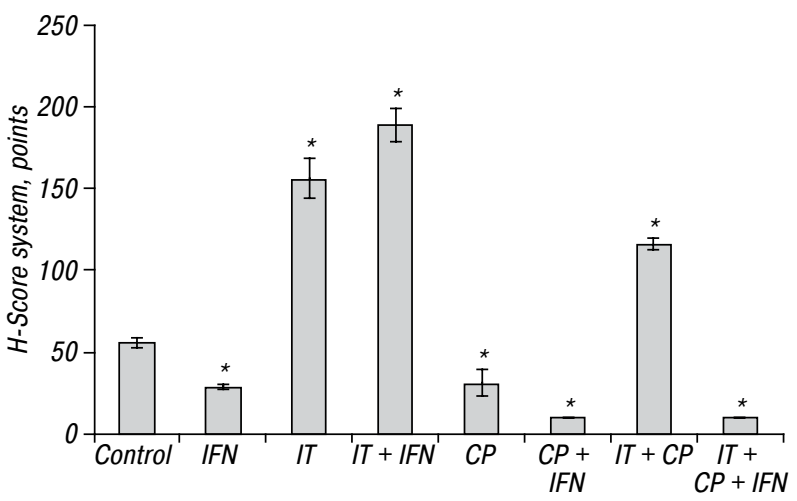

Fig. 5. Immunocytochemical analysis of ERCC1 expression in HT-29 cells after prolonged ( 30 days) exposure to the subtoxic doses of ACD. ${ }^{*} p<0.05$ compared with control cells

The study of CD44 expression in HT-29 cells has shown significantly increased number of CD44-positive cells treated with CP and IT, but not IFN (Table 3) compared to the cells of mesenchymal phenotype (COLO 205) in which the number of CD44-positive significantly decreased after exposure to $\mathrm{CP}$ and $\mathrm{ACD}$ combined with IFN (Table 2).

The analysis revealed the location of transcription factor Slug only in the cytoplasm of HT-29 cells and in control cells - at a low level (since this factor is characteristic of mesenchymal cells), while after the action of CP the number of Slug-positive cells significantly increased. The additional effect of IFN significantly reduced the number of Slug expressing cells. A similar trend was observed in the study of COLO 205 cells: the highest number of cells with Slug expression was observed after their exposure to CP (although lower than in control cells), which was significantly reduced by the additional effect of IFN (Table 2). These facts require further investigations of crosstalk between IFN system and reparation and adhesion proteins, as far as they indicate the capability of IFN to exert antitumor action dependent on the EMT status of tumor cells.

Also, we have investigated the influence of ACD on a newly established cell line 3C-P derived from ascitic fluid of the patient with colon cancer. Its growth kinetics after more than 20 passages in vitro is shown in Fig. 6. The cells of $3 \mathrm{C}-\mathrm{P}$ line are characterized by quick proliferation with a maximal growth density on day 4 and then a significant reduction in the number of living cells was observed.
3C-P cells were exposed to low-dose IFN, CP, IT and then immunocytochemical analysis of the markers associated with EMT has been conducted (Table 4). This investigation was of special importance because these cells underwent a small number of doublings in vitro, yet are heterogeneous and did not accumulate a large number of mutations. Interestingly, in the case of IFN combined with IT in subtoxic concentrations total cell death was registered, but not if these agents were used in monoregimen.

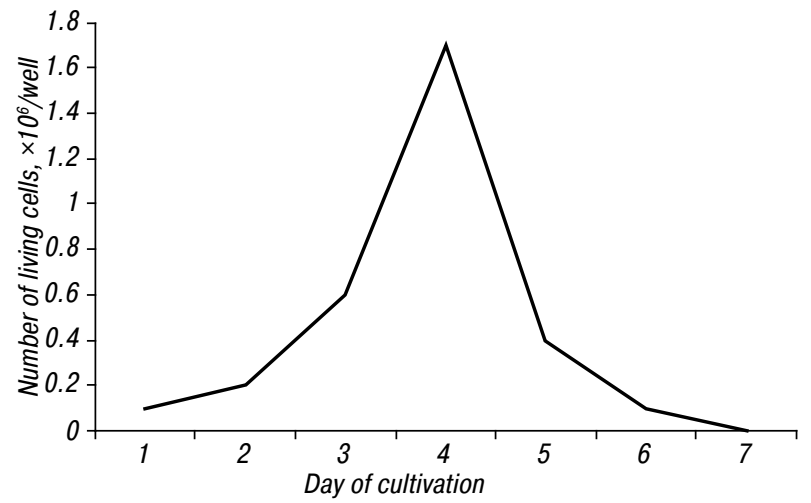

Fig. 6. Kinetics of growth (number of live cells) of the newly established 3C-P cell line

Similarly, to the cells with a mesenchymal phenotype, COLO 205, a trend for reduction of the number of CD44-positive cells after exposure of 3C-P to IFN was observed, while other ACD had no effect on the CD44 expression. The number of $\beta$-catenin-positive cells significantly increased after exposure of $3 \mathrm{C}-\mathrm{P}$ cells to IFN (and in the case of its combination with $\mathrm{CP}$ ) and IT, while CP did not influence the marker expression (Table 4). Significantly decreased number of vimentinpositive cells after the action of IFN was registered, while the action of IT resulted in increased number of cells expressing this antigen.

Table 4. Immunophenotypic profile of $3 \mathrm{C}-\mathrm{P}$ cells after prolonged exposure to the subtoxic doses of ACD and IFN

\begin{tabular}{lccccc}
\hline \multirow{3}{*}{ Antigen } & \multicolumn{5}{c}{ Drugs } \\
\cline { 2 - 6 } & Control & \multicolumn{5}{c}{ CP } & IT & IFN & CP + IFN \\
\cline { 2 - 6 } & \multicolumn{5}{c}{ Points (H-Score) } \\
\hline CD44 & $194 \pm 6$ & $210 \pm 15$ & $192 \pm 8$ & $124 \pm 10^{\star *}$ & $215 \pm 22$ \\
$\beta$-catenin & $32 \pm 11$ & $24 \pm 2$ & $180 \pm 15^{\star * *}$ & $140 \pm 4^{\star \star *}$ & $125 \pm 15^{\star}$ \\
Vimentin & $180 \pm 11$ & $132 \pm 3^{\star}$ & $262 \pm 7^{\star *}$ & $80 \pm 14^{\star}$ & $112 \pm 4^{*}$ \\
\hline
\end{tabular}

Note: The difference vs control $3 C$-P cells is statistically significant; ${ }^{*} p<0.02$; ${ }^{* \star} p<0.01 ;{ }^{* *} p<0.005$.

Thus, immunocytochemical analysis showed that in 3C-P cells IFN inhibited manifestation of the mesenchymal phenotype, while IT and CP had a multidirectional impact on the expression of EMT markers.

Next, we analyzed whether long exposure of the cells to low-dose ACD in vitro affected their drug resistance. For this purpose, we compared the IC50 values of colon cancer cells to standard (high) doses ACD before and after long-term low-dose treatment and revealed that IC50 values did not differ significantly in all studied cell lines (data not shown).

At last, the cytogenetic analysis of COLO 205 cells (number of mitoses, a number of cells with MN, apoptotic cells and cells with nuclear protrusions) has been conducted (Fig. 7). As markers of genotoxic events 
and chromosomal instability, there are used counting of cells with $\mathrm{MN}$ and other nuclear abnormalities, such as nucleoplasmic bridges, nuclear buds, nuclear "tails", dumbbell nucleus [21]. MN are formed mainly from acentric chromosomal fragments or individual chromosomes that are not included into the daughter nuclei during telophase [22]. Since MN and various nuclear abnormalities are the results of clastogenic and aneugenic events, the counting these abnormalities in cells is a convenient method for evaluation of cytogenetic instability in vitro after exposure to different chemical agents [23-27].
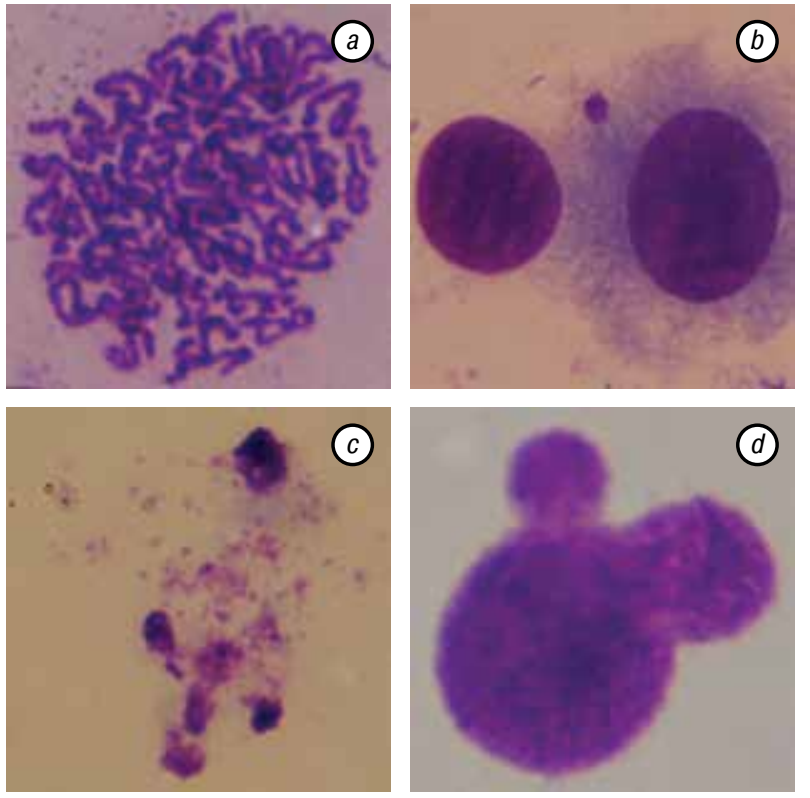

Fig. 7. Cytogenetic characteristics of COLO 205 cell line: a) mitosis, $b$ ) cell with $\mathrm{MN}, c$ ) apoptosis, $d$ ) nuclear protrusion

In our study, it was found that control COLO 205 cells have a relatively high cytogenetic stability - the number of cells with $\mathrm{MN}$ was $1 \%$, cells with protrusions $9 \%$, relatively high proliferative activity of cells with mitosis frequency $14 \%$ (Table 5). After cultivations with $\mathrm{CP}, \mathrm{IT}$, and IFN at subtoxic doses, the significant increase of the COLO 205 cells with MN and inhibition of mitosis $(p<0.05)$ as well as a trend for accumulation of the cells with nuclear abnormalities were found (Table 5).

Table 5. Cytogenetic characteristics of COLO 205 cells after their prolonged exposure to subtoxic doses of ACD and IFN

\begin{tabular}{lcccc}
\hline \multirow{2}{*}{$\begin{array}{c}\text { Cytogenetic } \\
\text { characteristics }\end{array}$} & \multicolumn{4}{c}{ Drugs } \\
\cline { 2 - 5 } & Control & \multicolumn{4}{c}{ CP } & IT & IFN \\
\cline { 2 - 5 } & \multicolumn{4}{c}{ Frequency of cells (\%o) } \\
Cells with MN & $1.33 \pm 1.5$ & $7.00 \pm 1.7^{*}$ & $7.00 \pm 1.0^{*}$ & $7.00 \pm 1.0^{*}$ \\
Mitosis & $13.67 \pm 1.5$ & $4.33 \pm 1.5^{\star}$ & $6.67 \pm 1.1^{*}$ & $2.67 \pm 0.6^{*}$ \\
Apoptosis & $8.67 \pm 1.5$ & $9.00 \pm 1.0$ & $7.67 \pm 1.5$ & $10.33 \pm 0.6$ \\
Nuclear protrusions & $9.33 \pm 1.5$ & $12.33 \pm 1.1$ & $9.67 \pm 1.1$ & $10.67 \pm 1.5$ \\
\hline
\end{tabular}

Note: The difference is statistically significant compared with control COLO 205 cells; ${ }^{*} p<0.05 ;{ }^{* *} p<0.01$.

Thus, such exposure on the cells resulted in genotoxic events. The IT + IFN combination had the most significant genotoxic effect in COLO 205 cells causing the decrease of mitotic activity $(p<0,05)$ and accumulation of cells with $\mathrm{MN}(p<0.001)$ which is almost 40 times higher than the value in the control cells (Table 6). The combination of IT + CP caused lower cytogenetic disorders possibly due to the induction of apoptosis, which is 2 times higher than in control cells $(p<0.001)$, however, led to significant genotoxic effect, in particular, decrease of proliferative activity $(p<0.05)$ and high frequency of cells with MN $(p<0.05)$. The combination of IFN + CP had the lowest genotoxicity of all drug combinations (Table 6). So, prolonged treatment of COLO 205 cells with ACD in subtoxic doses resulted in genotoxic effects, i.e. reduction of cell proliferation and accumulation of cells with $\mathrm{MN}$.

Table 6. Cytogenetic characteristics in COLO 205 cell line after prolonged exposure to subtoxic doses of ACD, their combinations and IFN

\begin{tabular}{lccccc}
\hline \multicolumn{5}{c}{ Drugs } \\
\hline $\begin{array}{l}\text { Cytogenetic } \\
\text { characteris- }\end{array}$ & Control & CP + IFN & IT + IFN & CP + IT & $\begin{array}{c}\text { CP }+ \text { IT + } \\
\text { tics }\end{array}$ \\
\cline { 2 - 6 } \multicolumn{5}{c}{ Frequency of cells $(\%)$} \\
\hline Cells with MN & $1.33 \pm 1.5$ & $6.00 \pm 0.00^{\star}$ & $38.67 \pm 2.5^{\star \star}$ & $14.67 \pm 2.0^{\star}$ & $12.00 \pm 1.7^{\star}$ \\
Mitosis & $13.67 \pm 1.5$ & $3.5 \pm 0.41^{\star}$ & $3.33 \pm 0.6^{\star}$ & $3.33 \pm 0.6^{\star}$ & $3.33 \pm 1.1^{\star}$ \\
$\begin{array}{l}\text { Apoptosis } \\
\text { Nuclear pro- }\end{array}$ & $8.67 \pm 1.5$ & $9.00 \pm 0.82$ & $8.00 \pm 1.0$ & $18.67 \pm 1.5^{\star \star}$ & $9.67 \pm 0.67$ \\
trusions & $9.33 \pm 1.5$ & $10.50 \pm 0.41$ & $8.00 \pm 1.1$ & $11.00 \pm 1.0$ & $7.00 \pm 1.0$ \\
\hline
\end{tabular}

Note: The difference is statistically significant compared with control COLO 205 cells; ${ }^{*} p<0.05 ;{ }^{* \star} p<0.01$.

\section{CONCLUSION}

The data showed that the direct prolonged action of the low doses of ACD on human colon cancer cells resulted in the suppression of cell proliferation, colony-forming activity in soft agar, expression of EMTassociated markers and significant cytogenetic changes. The sensitivity of colon cancer cells to ACD in standard cytotoxic concentrations did not change after prolonged low-dose exposure.

\section{REFERENCES}

1. Zhukov NV. The current state of anti-angiogenic therapy. Targeted therapy without a target? Prakt Oncol 2007; 8: 164-73 (in Russian).

2. Chubenko VA. Perspective methods of treatment of malignant neoplasms. Prakt Oncol 2007; 8: 228-34 (in Russian).

3. Chekhun VF, Maksim'yak GI, Zhylchuk VE, et al. The ways to improve drug therapy of rectal cancer patients with liver metastases: advantages of metronomic regime of chemotherapy. Oncologiya 2011; 13: 229-33 (in Russian).

4. Loven D, Hasnis E, Bertolini F, Shaked Y. Low-dose metronomic chemotherapy: from past experience to new paradigms in the treatment of cancer. Drug Discov Today 2013; 18: 193-201.

5. Hanahan D, Bergers G, Bergsland E. Less is more, regularly: metronomic dosing of cytotoxic drugs can target tumor angiogenesis in mice. J Clin Invest 2000; 105: 1045-7.

6. Bocci G, Nicolaou KC, Kerbel RS. Protracted low-dose effects on human endothelial cell proliferation and survival in vitro reveal a selective antiangiogenic window for various chemotherapeutic drugs. Cancer Res 2002; 62: 6938-43.

7. He K, Jin K, Wang H, Teng L. Anti-angiogenic therapy for colorectal cancer: on the way to getting better! Hepatogastroenterology 2012; 59: 1113-7.

8. Bocci G, Francia G, Man S, et al. Thrombospondin 1, a mediator of the antiangiogenic effects of low-dose metronomic chemotherapy. Proc Natl Acad Sci USA 2003; 100: 12917-22.

9. Lykhova A, Bezdenezhnykh N, Semesiuk N, et al. Loss of malignancy in mouse melanoma cells by long-term impact of recombinant interferon-beta in vitro is associated with $\mathrm{N}$ and VE-cadherins suppression without inhibition expression of epithelial-mesenchymal transition transcription factors Twist and Slug. J Anal Oncol 2014; 3: 136-45. 
10. Kudryavets YuI, Bezdenezhnykh NO, Lykhova OO, et al. The role of interferon as a modifier of epithelial-mesenchymal transition in tumor cells. Exp Oncol 2011; 33: 178-81.

11. Animal Cell Culture. In: Freshney RI, eds. A practical approach. Moscow: Binom, 2010. 714 p. (in Russian).

12. McClelland RA, Wilson $D$, Leake R, et al. A multicentre study into the reliability of steroid receptor immunocytochemical assay quantification. British Quality Control Group. Eur J Cancer 1991; 27: 711-5.

13. Kovalova O, Bezdeneznykh N, Kudryavets Yu. Nonchromosomal cytogenetic analysis of mammal somatic cells. Biopolym Cell 2013; 29: 33-41.

14. Allegrini G, Di Paolo A, Cerri E, et al. Irinotecan in combination with thalidomide in patients with advanced solid tumors: a clinical study with pharmacodynamic and pharmacokinetic evaluation. Cancer Chemother Pharmacol 2006; 58: 585-93.

15. Ogata $\mathrm{Y}$, Mori S, Ishibashi N, et al. Metronomic chemotherapy using weekly low-dosage CPT-11 and UFT as postoperative adjuvant therapy in colorectal cancer at high risk to recurrence. J Exp Clin Cancer Res 2007; 26: 475-82.

16. Liu S, Cong Y, Wang D, et al. Breast cancer stem cells transition between epithelial and mesenchymal states reflective of their normal counterparts. Stem Cell Reports 2013; 2: 78-91.

17. Wang Y, Shi J, Chai K, et al. The Role of Snail in EMT and tumorigenesis. Curr Cancer Drug Targets 2013; 13: $963-72$.

18. Kalluri R, Weinberg RA. The basics of epithelialmesenchymal transition. J Clin Invest 2009; 119: 1420-8.

19. Viguier $\mathrm{J}$, Boige $\mathrm{V}$, Miquel $\mathrm{C}$, et al. ERCC1 codon 118 polymorphism is a predictive factor for oxaliplatin/5- fluorouracil combination chemotherapy in patients with advanced colorectal cancer. Clin Cancer Res 2005; 11: 6212-7.

20. Milovic-Kovacevic M, Srdic-Rajic T, Radulovic S, et al. Expression of ERCC1 protein in biopsy specimen predicts survival in advanced ovarian cancer patients treated with platinum-based chemotherapy. J BUON 2011; 16: 708-14.

21. Fenech M, Kirsch-Volders M, Natarajan AT, et al. Molecular mechanisms of micronucleus, nucleoplasmic bridge and nuclear bud formation in mammalian and human cells. Mutagenesis 2011; 26: 125-32.

22. Fenech M. The lymphocyte cytokinesis-block micronucleus cytome assay and its application in radiation biodosimetry. Health Phys 2010; 98: 234-43.

23. Gisselsson D. Classification of chromosome segregation errors in cancer. Chromosoma 2008; 117: 511-9.

24. Zyss D, Gergely F. Centrosome function in cancer: guilty or innocent? Trends Cell Biol 2009; 19: 334-46.

25. Surrallés J, Catalán J, Creus A, et al. Micronuclei induced by alachlor, mitomycin-C and vinblastine in human lymphocytes: presence of centromeres and kinetochores and influence of staining technique. Mutagenesis 1995; 10: $417-23$.

26. Wu J, Lyons GH, Graham RD, Fenech MF. The effect of selenium, as selenomethionine, on genome stability and cytotoxicity in human lymphocytes measured using the cytokinesis-block micronucleus cytome assay. Mutagenesis 2009; 24: 225-32.

27. Duan H, Leng S, Pan Z, et al. Biomarkers measured by cytokinesis-block micronucleus cytome assay for evaluating genetic damages induced by polycyclic aromatic hydrocarbons. Mutat Res 2009; 677: 93-9. 